knowledge, often related to the needs and opportunities of the regions, have been made. There has also been a small but steadily increasing flow of graduates who will have a profound influence on the development of their nations.

All this will be of increasing importance as more territories move to independence and increasing efforts are made to solve the problems of government in multi-racial territories. More university institutions will probably be required, and Dr. Cook wisely suggests that these need not be conceived on precisely the same lines as the existing institutions. There is room for experiment, and perhaps especially in ways that have closer regard to the financial resources of newly independent countries. What matters most is that in giving careful attention to the traditional cultures of the countries and to their expanding needs, high academic standards should be maintained and the university traditions which have stood the test of time should be scrupulously observed. For that reason alone, universities in the rapidly developing countries should be the more careful not to become embroiled in political controversy, and to ensure that their legitimate studies of political, economic and social questions should be undertaken in no partisan spirit. Nor may it be too much to hope that in the measure in which these new universities meet the needs of the independent territories, and especially of the multi-racial communities, they will demon. strate the futility of the South African Government's present university policy, and perhaps even cause its reversal before South African academic traditions are destroyed and irreparable damage done to its universities.

\section{ANTIBIOTICS FROM A NOVEL ANGLE}

\section{Antibiotics}

Their Chemistry and Non-Medical Uses. Edited by Dr. Herbert S. Goldberg. Pp. $\mathrm{x}+608$. (Princeton, N.J.: D. Van Nostrand Company, Inc., London: D. Van Nostrand Company, Ltd., 1959.) 112s. $6 d$.

$\mathrm{N}$ a foreword to this very welcome book, Dr. Paul $\mathrm{R}$. Burkholder, the discoverer of chloromycetin, says : "For some time past, all of us have been certain about one aspect of antibiotic science and that is the great need for a new kind of book which would summarize the remarkable advances that have taken place recently" and the reviewer, who is in full agreement, would like to add "particularly in their non-medical uses". The book is the work of six American authors, all of whom are well known in antibiotic science. It consists of an introduction and six chapters, each of which is a complete monograph in itself. An unusual and very useful feature of the book is the large number of references-some two thousand in all-occupying a total of 261 pages and amounting to about 43 per cent of the book. The references given in the introduction (216 in number) and in the opening chapter on the chemistry of antibiotics (566) give the full title of the paper referred to in the text together with the usual details.
In the remaining five chapters, however, very informative abstracts of the contents of the papers are also given.

The introduction deals with the history of antibiotics, their economic import, natural occurrence, effects and mode of action. The opening chapter (84 pages) admirably succeeds in summarizing the chemistry of the penicillins, streptomycin and related antibiotics, chloromycetin, the tetracycline group, the macrolides, novobiocin, polyene and polypeptide antibiotics.

The growth stimulation and general effects on the nutrition of domestic animals and birds is discussed in the following chapter (59 pages; 545 references). The magnitude and importance of this aspect of antibiotics may be judged from the fact that in $\mathbf{1 9 5 4}$ more than 20 per cent (value 25 million dollars) of all antibiotics produced in the United States were used in animal feed supplements.

Botanists, and particularly plant pathologists and physiologists, will find the article on "The Influence of Antibiotics on Plants and Plant Disease Control" (78 pages ; 376 references) a full and authoritative account of the subject. It is certainly surprising to learn that at least thirty-nine different antibiotics have been studied in the control of plant bacterial and fungal pathogens.

The texts of the remaining three chapters are relatively short. Chapter 5 ( 22 pages ; 283 references, which unfortunately are not numbered) deals with antibiotics in food preservation, that is, in canned foods, fresh foods including meats, poultry, fish, fruit and vegetables, dairy products and yeast fermentations. Laboratory workers in microbiology will particularly welcome chapter 6 (18 pages; 96 references) on the uses of antibiotics in the isolation in pure culture and cultivation of micro-organisms from the complex mixtures in which they normally occur, for example, bacteria, fungi including plant pathogens, protozoa, viruses and rickettsiae. The book eloses with an authoritative article ( 22 pages; 75 references) on the public health significance of non-medical uses of antibiotics, particularly in foods for human consumption. We may however take some comfort from the author's opinion that "one must conclude that the seriousness of the public health hazards of antibiotic residues in food has been overstated".

I believe that this book will completely satisfy the need expressed earlier for a new kind of book on antibiotic science. Hatrold Raistrick

\section{BIOCHEMICAL PRACTICE}

\section{Biochemical Preparations}

Vol. 6. Edited by Carl S. Vestling. Pp. ix +105. (New York : John Wiley and Sons, Inc.; London : Chapman and Hall, Ltd., 1958.) 42s. net.

\section{Methods of Biochemical Analysis}

Vol. 7. Edited by Prof. David Glick. Pp. ix +353 . (New York : Interscience Publishers, Inc.; London : Interscience Publishers, Ltd., 1959.) 72s.

THE latest volume in the valuable series of "Biochemical Preparations" contains detailed descriptions of carefully checked methods for the preparation of the following: crystalline animal cytochrome $e$, deoxyribonucleic acid, 2,3-diphosphoglyceric acid, L- $\alpha$-glycerophosphorylcholine, 3 - 